\title{
Interactive comment on "Estimation of fire-induced carbon emission from Equatorial Asia in 2015 by using in situ aircraft and ship observations" by Yosuke Niwa et al.
}

Yosuke Niwa et al.

niwa.yosuke@nies.go.jp

Received and published: 5 May 2021

The comment was uploaded in the form of a supplement:

https://acp.copernicus.org/preprints/acp-2020-1239/acp-2020-1239-AC2-

supplement.pdf

Interactive comment on Atmos. Chem. Phys. Discuss., https://doi.org/10.5194/acp-2020-1239, 2020. 